\title{
Nationwide trends and regional/hospital variations in open versus endovascular repair of thoracoabdominal aortic aneurysms
}

\author{
Joshua M. Liao, BS, ${ }^{\text {a }}$ Faisal G. Bakaeen, MD, ${ }^{\text {a,b }}$ Lorraine D. Cornwell, MD, ${ }^{\text {a }}$ Kiki Simpson, MS, ${ }^{a}$ \\ Scott A. LeMaire, MD, ${ }^{\mathrm{a}, \mathrm{b}}$ Joseph S. Coselli, MD, ${ }^{\mathrm{a}, \mathrm{b}}$ and Danny Chu, MD ${ }^{\mathrm{a}, \mathrm{b}}$
}

\begin{abstract}
Objectives: Thoracic endovascular aortic repair (TEVAR) has been gaining popularity for the treatment of thoracoabdominal aortic aneurysm (TAAA). We used a nonvoluntary database to examine national trends and regional/hospital variations in the use of TEVAR and open thoracic aortic repair (OTAR) for TAAA.
\end{abstract}

\begin{abstract}
Methods: From the 2005-2008 Nationwide Inpatient Sample database, we identified all patients with the diagnosis of TAAA who were treated with TEVAR or OTAR. Rates of these procedures were compared between years, across geographic regions, and between hospitals of various bed sizes.
\end{abstract}

Results: Over the study period, the rate of OTAR remained relatively stable (range, 7.5/100 patients in 2005 to $10.1 / 100$ patients in 2008; $P=.26$ ), whereas the rate of TEVAR increased dramatically (range, $1.4 / 100$ patients in 2005 to $6.3 / 100$ patients in 2008; $P<.0001)$. In 2008, 29\% (211) of all TEVAR procedures and $11 \%(130)$ of all OTAR procedures were performed in western regions of the United States $(P=.03)$. Additionally, $13 \%(95)$ of all TEVAR procedures and 3\% (35) of all OTAR procedures were performed in smaller hospitals $(P<.0001)$.

Conclusions: The use of TEVAR for TAAA repair increased significantly over the study period, whereas OTAR rates remained relatively stable. Our findings suggest that more patients who were otherwise not surgical candidates or did not have traditional surgical indications for OTAR were treated with TEVAR, most commonly in regions or hospitals where OTAR is less often performed. Given the complexity of TAAA cases, these results may have significant implications for patient safety in the current era of heightened health care scrutiny. (J Thorac Cardiovasc Surg 2012;144:612-6)

After endovascular techniques were developed for the management of abdominal aortic aneurysms in 1991, they competed with open aortic repair and have become the primary treatment modality for many patients with isolated aortic aneurysms. ${ }^{1-3}$ Endovascular interventions for aneurysm repair were further refined after the technology for thoracic endovascular aortic repair (TEVAR) was approved by the US Food and Drug Administration in 2005 for use in the repair of thoracic aortic aneurysms, ${ }^{4}$ leading to an increased use of stent grafts in repairing some thoracic aortic aneurysms. Since then, TEVAR has been rapidly gaining popularity.

Preliminary short-term data regarding the use of TEVAR to treat thoracic aortic aneurysms have been promising. ${ }^{5}$ Intermediate outcomes for TEVAR in the treatment of thoracic aortic aneurysms, first described in several single-center studies, ${ }^{6}$ were further elucidated in a nationwide study that aimed to

From Baylor College of Medicine ${ }^{\mathrm{a}}$ and the Texas Heart Institute at St Luke's Episcopal Hospital, ${ }^{\mathrm{b}}$ Houston, Tex.

Disclosures: Authors have nothing to disclose with regard to commercial support.

Read at the 37th Annual Meeting of The Western Thoracic Surgical Association, Colorado Springs, Colorado, June 22-25, 2011.

Received for publication June 21, 2011; revisions received Aug 8, 2011; accepted for publication Oct 21, 2011.

Address for reprints: Danny Chu, MD, Texas Heart Institute/Baylor College of Medicine, One Baylor Plaza, Houston, TX 77030 (E-mail: dchumd@gmail.com). $0022-5223 / \$ 36.00$

Copyright $(C) 2012$ Published by Elsevier Inc. on behalf of The American Association for Thoracic Surgery

http://dx.doi.org/10.1016/j.jtcvs.2011.10.098 address TEVAR's national utility and that associated TEVAR with better in-hospital outcomes, shorter lengths of stay, and fewer complications than open thoracic aortic repair (OTAR). ${ }^{7}$

Thoracoabdominal aortic aneurysm (TAAA) is a rare but complex and potentially lethal disease with relatively high perioperative morbidity and mortality. Historically, TAAA has required open surgical repair. ${ }^{8,9}$ The overall rupture rate is estimated to be as high as $26 \%,{ }^{10}$ and rupture is associated with an overall mortality rate of $20.3 \% .{ }^{11}$ Postrepair and perioperative mortality rates from experienced centers range from approximately $4 \%$ to $16 \%{ }^{12-16}$ Given the relatively high morbidity and mortality of open surgical TAAA repair, less-invasive TEVAR procedures with adjunctive surgical visceral vessel debranching (hybrid approach) and TEVAR alone with specialized branched endografts have slowly emerged as feasible and promising alternatives. ${ }^{17-20}$

However, little is known about regional and hospital variation in the use of TEVAR for the treatment of TAAA. We examined nationwide trends and attempted to determine whether there is any regional or hospital variation in the use of TEVAR versus OTAR for the treatment of TAAA.

\section{MATERIALS AND METHODS \\ Data Source}

Data were collected from the 2005-2008 Nationwide Inpatient Sample (NIS). The NIS is a database of hospital inpatient stays and is maintained by the Agency for Healthcare Research and Quality as part of the Healthcare Cost and Utilization Project (HCUP). ${ }^{21}$ The NIS is the largest all-payer 


\section{Abbreviations and Acronyms \\ HCUP = Healthcare Cost and Utilization Project \\ ICD- = International Classification of Diseases, \\ 9-CM Ninth Revision, Clinical Modification \\ NIS = Nationwide Inpatient Sample \\ OTAR = open thoracic aortic repair \\ TAAA $=$ thoracoabdominal aortic aneurysm \\ TEVAR $=$ thoracic endovascular aortic repair}

inpatient care database, representing $20 \%$ of all hospital discharges from nonfederal facilities within the United States. The NIS has numerous internal quality assurance procedures that check the consistency and validity of data points (http://www.hcup-us.ahrq.gov/db/quality.jsp). Furthermore, HCUP validates the NIS annually by comparing its contents with those of 2 similar databases, the National Hospital Discharge Survey and the Medicare Provider Analysis and Review, to assess potential biases in the dataset (http:// www.hcup-us.ahrq.gov/db/nation/nis/nisrelatedreports.jsp). The NIS contains data on approximately 8 million hospital stays each year from more than 1000 hospitals. Weights based on sampling probabilities for each stratum are used in the analysis to ensure that the hospitals studied are representative of all US hospitals. Five hospital sampling strata were defined according to hospital characteristics contained in the American Hospital Association Annual Survey of Hospitals. The stratification variables were geographic region (Appendix Table 1), location (urban or rural), teaching status, control (public or proprietary), and bed size (Appendix Table 2).

This study was approved by the Institutional Review Board of Baylor College of Medicine. The reported data conform to the data-use agreement for the NIS from the HCUP. Additional information about NIS is available from the Agency for Healthcare Research and Quality, which administers the database as part of the HCUP (http://www.hcup-us.ahrq.gov/nisoverview.jsp).

\section{Patient Selection}

Patient identification was based on the 2008 International Classification of Diseases, Ninth Revision, Clinical Modification (ICD-9-CM) diagnosis and procedure codes. ${ }^{22}$ We used the these codes to query the 2005-2008 NIS database for our patient selection. The ICD-9 diagnosis codes 4416 and 4417 were used to identify all patients with TAAA. Within this group of patients, the ICD-9 procedure codes 3835 and 3845 were used to identify patients who underwent OTAR only without any endovascular intervention, and procedure code 3973 was used to identify patients who underwent TEVAR with or without a hybrid debranching procedure. We excluded patients who underwent both TEVAR and OTAR during the same index hospitalization in an attempt to exclude emergency open conversions from our final analysis.

We found a total of 39,135 records of patients with the diagnosis of TAAA who were discharged from a hospital during the 4-year study period. Of these patients, 2911 underwent OTAR only, and 1838 underwent TEVAR alone with branched endografts or TEVAR with a hybrid visceral debranching procedure.

\section{Statistical Analysis}

NIS database discharge weights were used to produce national estimates for all analyses. Rates of TEVAR and OTAR were then compared by year, geographic region (Appendix Table 1), and hospital bed size (Appendix Table 2) by using the Rao-Scott $\chi^{2}$ test. All data were analyzed with SAS/STAT software, version 9.1, of the SAS System for the XP PRO platform (SAS Institute Inc, Cary, NC).

\section{RESULTS}

As shown in Figure 1, the rate of OTAR remained relatively stable over the study period (7.5/100 TAAA patients in $2005 \mathrm{vs}$
10.1/100 TAAA patients in 2008; $P=.26$ ). In contrast, the rate of TEVAR increased significantly, from 1.4/100 TAAA patients in 2005 to $6.3 / 100$ TAAA patients in $2008(P<.0001)$.

In the most recent data set (from 2008), 29\% of all TEVAR procedures were performed in western regions of the United States (as defined in Appendix Table 1), whereas only $11 \%$ of all OTAR procedures were performed in those regions (Table 1). Similarly, in 2008, $13 \%$ of all TEVAR procedures were performed in small bed size hospitals (as defined in Appendix Table 2), whereas only 3\% of all OTAR procedures were performed in small hospitals (Table 2).

\section{DISCUSSION}

We found that whereas OTAR rates remained relatively stable over the 4-year study period, TEVAR rates significantly increased over the same period for the treatment of TAAA. Moreover, the rates of TEVAR and OTAR varied among regions and by hospital bed size, in that more TEVAR procedures than OTAR procedures were performed in western regions of the United States and in smaller hospitals across the country.

Because of both the minimal invasiveness of TEVAR compared with OTAR and patient-driven demand for TEVAR technology, TEVAR rates for the treatment of TAAA rapidly increased between 2005 and 2008, whereas rates of OTAR for TAAA remained relatively unchanged during the same period. Although these results are not unexpected, the regional and hospital variation in the use of these procedures is a novel finding and may have significant implications.

Open surgical TAAA repairs are complex surgical procedures, the outcomes of which have been shown to be best at high-volume centers with high-volume surgeons. ${ }^{23}$ For this reason, OTAR for TAAA repair often requires a dedicated team of surgeons, anesthesiologists, ancillary support staff, and hospital resources to achieve optimal outcome. Although TEVAR is less invasive than OTAR, intraoperative conversion to emergency OTAR - the probability of which is not insignificant — carries a high mortality and morbidity rate. ${ }^{24}$

Our study shows significant regional and hospital variation in the rates of TEVAR and OTAR procedures for the treatment of TAAA. Specifically, a higher percentage of TEVAR procedures than OTAR procedures was performed in western regions of the United States and in smaller hospitals (Tables 1 and 2). When complications from TEVAR procedures occur in regions or hospitals where OTAR is less commonly performed, emergency open conversion must be done in a setting where resources and experience may be limited. This situation is probably not uncommon, because conversion to OTAR is necessary in approximately $4 \%$ of TEVAR procedures performed to treat thoracic aortic disease of any sort. ${ }^{24}$ The outcomes of these emergency conversions may be compromised in such cases.

Regional variations in the rates of TEVAR identified in our study may have been due to population density variance 


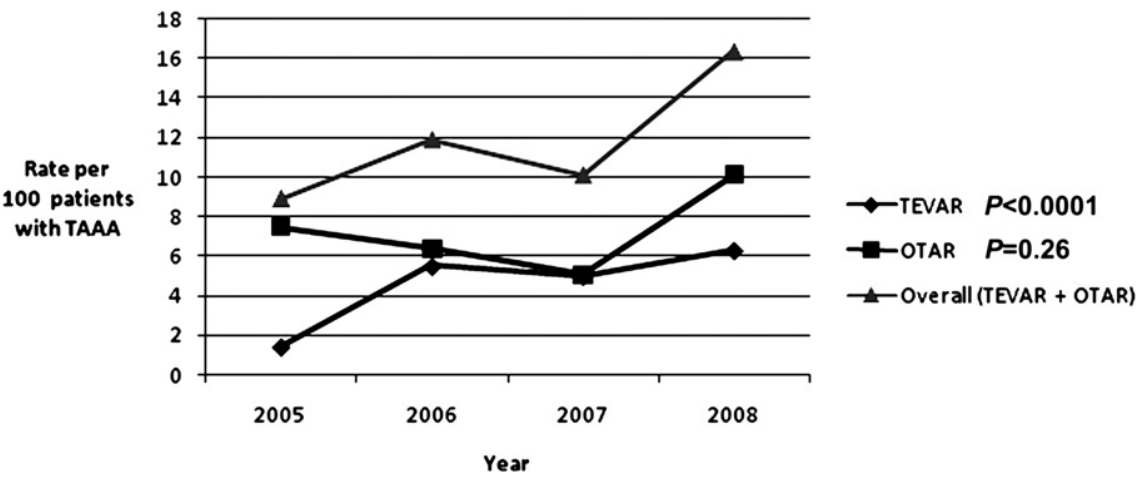

FIGURE 1. Nationwide trends in the rate of open versus endovascular repair of thoracoabdominal aortic aneurysm (TAAA). TEVAR, Thoracic endovascular aortic repair; OTAR, open thoracic aortic repair.

across different census tracts of the United States. Specifically, western and northeastern regions account for approximately $22 \%$ and $17 \%$ of the overall US population, respectively (www.census.gov/prod/cen2010/briefs/ c2010br-01.pdf). Assuming equal prevalence of TAAA across the country, each of these 2 regions are performing $7 \%$ more TEVAR than expected when compared with their population densities (Table 1). Along the same line of reasoning, the western region is performing $11 \%$ fewer OTAR procedures while the northeastern region is performing 20\% more OTAR procedures (Table 1). Even after adjusting for population density differences, our study continued to support the observation that TEVAR procedures are being performed more commonly in regions (such as the west) where OTAR is less often performed. This observation along with hospital variation in TEVAR/ OTAR procedures ultimately may have significant patient safety implications, as previously suggested.

Our study is subject to the limitations inherent in a retrospective review and in the use of an administrative database like that of the NIS. As such, we were not able to obtain specific operative procedure details (pure endograft vs hybrid) or clinical outcome information, and there may have been reporting bias owing to coding errors. However, the focus of our study was on the health-service implications of trends in TEVAR and OTAR use, not on clinical outcomes, and any potential reporting bias would have been equally distributed between the TEVAR and OTAR cases. Also, although the NIS database provides a significant amount of information on hospital characteristics, it does not adjust for the volume

TABLE 1. Regional variation in the treatment of thoracoabdominal aortic aneurysms in 2008

\begin{tabular}{|c|c|c|c|c|c|}
\hline \multirow[b]{2}{*}{ Procedure } & \multicolumn{4}{|c|}{ Region } & \multirow{2}{*}{$\begin{array}{c}P \\
\text { value }\end{array}$} \\
\hline & Northeast & Midwest & South & West & \\
\hline OTAR & $436(37 \%)$ & $353(30 \%)$ & $259(22 \%)$ & $130(11 \%)$ & .03 \\
\hline TEVAR & $176(24 \%)$ & $124(17 \%)$ & $219(30 \%)$ & $212(29 \%)$ & \\
\hline
\end{tabular}

US geographic regions are those described on the Nationwide Inpatient Sample database Web site (http://www.hcup-us.ahrq.gov/db/vars/h_region/nisnote.jsp). OTAR, Open thoracic aortic repair; TEVAR, thoracic endovascular aortic repair. of cases performed by individual surgeons, nor does it include specific data regarding the anatomic extent of each patient's TAAA. Nonetheless, the large sample size of our database allowed us to identify significant regional and hospital variations. Also, the nonvoluntary nature of the NIS database provides a novel "real-world" snapshot of TEVAR/OTAR trends and variations in the treatment of TAAA.

Future research efforts should focus on exploring the mechanisms underlying these regional and hospital variations. Previous research has suggested that regionalizing procedures associated with high perioperative mortality rates such as open surgical TAAA repair and endovascular repair for ruptured abdominal aortic aneurysms would improve outcomes. ${ }^{23,25}$ However, it is unclear whether this would also be true for TAAA repairs with TEVAR. As TEVAR technology improves with the advent of customizable visceral branched endografts, the endovascular skills necessary for TAAA TEVAR may become increasingly difficult to master. Regionalization of TAAA patients to high-volume specialized aortic centers of excellence may be needed to achieve excellent outcomes and provide optimal patient safety.

In conclusion, our results suggest that there are significant national trends and variations in the use of TEVAR versus OTAR for TAAA repair, and these differences may have important health care and patient safety implications. Further work is needed to identify the mechanisms that underlie these observed variations and to determine what implications these disparities have for patient outcomes.

TABLE 2. Hospital variation in the treatment of thoracoabdominal aortic aneurysms in 2008

\begin{tabular}{lllll}
\hline & \multicolumn{3}{c}{ Hospital bed size } & \multirow{P}{*}{} \\
\cline { 2 - 4 } Procedure & Small & Medium & Large & value \\
\hline OTAR & $35(3 \%)$ & $47(4 \%)$ & $1096(93 \%)$ & $<.0001$ \\
TEVAR & $95(13 \%)$ & $80(11 \%)$ & $556(76 \%)$ & \\
\hline
\end{tabular}

Hospital bed size categories are those described on the Nationwide Inpatient Sample database Web site (http://www.hcup-us.ahrq.gov/db/vars/hosp_bedsize/nisnote.jsp). $O T A R$, Open thoracic aortic repair; TEVAR, thoracic endovascular aortic repair. 
We thank Stephen N. Palmer, PhD, ELS, for his editorial assistance in the preparation of this manuscript.

\section{References}

1. Dake MD, Miller DC, Semba CP, Mitchell RS, Walker PJ, Liddell RP. Transluminal placement of endovascular stent-grafts for the treatment of descending thoracic aortic aneurysms. $N$ Engl J Med. 1994;331:1729-34.

2. Parodi JC, La Mura R. Endovascular aortic devices: the Parodi and Palmaz system. Surg Technol Int. 1996;5:290-6.

3. Parodi JC, Palmaz JC, Barone HD. Transfemoral intraluminal graft implantation for abdominal aortic aneurysms. Ann Vasc Surg. 1991;5:491-9.

4. Bavaria JE, Appoo JJ, Makaroun MS, Verter J, Yu ZF, Mitchell RS. Endovascular stent grafting versus open surgical repair of descending thoracic aortic aneurysms in low-risk patients: a multicenter comparative trial. J Thorac Cardiovasc Surg. 2007;133:369-77.

5. Melissano G, Civilini E, de Moura MR, Calliari F, Chiesa R. Single center experience with a new commercially available thoracic endovascular graft. Eur J Vasc Endovasc Surg. 2005;29:579-85.

6. Stone DH, Brewster DC, Kwolek CJ, Lamuraglia GM, Conrad MF, Chung TK, et al. Stent-graft versus open-surgical repair of the thoracic aorta: mid-term results. J Vasc Surg. 2006;44:1188-97.

7. Gopaldas RR, Huh J, Dao TK, LeMaire SA, Chu D, Bakaeen FG, et al. Superior nationwide outcomes of endovascular versus open repair for isolated descending thoracic aortic aneurysm in 11,669 patients. J Thorac Cardiovasc Surg. 2010; 140:1001-10.

8. Crawford ES, Crawford JL, Safi HJ, Coselli JS, Hess KR, Brooks B, et al. Thoracoabdominal aortic aneurysms: preoperative and intraoperative factors determining immediate and long-term results of operations in 605 patients. $J$ Vasc Surg. 1986;3:389-404.

9. Svensson LG, Crawford ES, Hess KR, Coselli JS, Safi HJ. Experience with 1509 patients undergoing thoracoabdominal aortic operations. J Vasc Surg. 1993;17:357-68.

10. Juvonen T, Ergin MA, Galla JD, Lansman SL, Nguyen KH, McCullough JN, et al. Prospective study of the natural history of thoracic aortic aneurysms. Ann Thorac Surg. 1997;63:1533-45.

11. Derrow AE, Seeger JM, Dame DA, Carter RL, Ozaki CK, Flynn TC, et al. The outcome in the United States after thoracoabdominal aortic aneurysm repair, renal artery bypass, and mesenteric revascularization. J Vasc Surg. 2001;34:54-61.

12. Cambria RP, Clouse WD, Davison JK, Dunn PF, Corey M, Dorer D. Thoracoabdominal aneurysm repair: results with 337 operations performed over a 15-year interval. Ann Surg. 2002;236:471-9.
13. Estrera AL, Miller CC III, Huynh TT, Porat E, Safi HJ. Neurologic outcome after thoracic and thoracoabdominal aortic aneurysm repair. Ann Thorac Surg. 2001; 72:1225-31.

14. LeMaire SA, Miller CC III, Conklin LD, Schmittling ZC, Coselli JS. Estimating group mortality and paraplegia rates after thoracoabdominal aortic aneurysm repair. Ann Thorac Surg. 2003;75:508-13.

15. Rectenwald JE, Huber TS, Martin TD, Ozaki CK, Devidas M, Welborn MB, et al Functional outcome after thoracoabdominal aortic aneurysm repair. $J$ Vasc Surg. 2002;35:640-7.

16. Wong DR, Parenti JL, Green SY, Chowdhary V, Liao JM, Zarda S, et al. Open repair of thoracoabdominal aortic aneurysm in the modern surgical era: contemporary outcomes in 509 patients. J Am Coll Surg. 2011;212:569-79; discussion 579-81.

17. Greenberg R, Eagleton M, Mastracci T. Branched endografts for thoracoabdominal aneurysms. J Thorac Cardiovasc Surg. 2010;140(6 Suppl):S171-8.

18. Hughes GC, Nienaber JJ, Bush EL, Daneshmand MA, McCann RL. Use of custom Dacron branch grafts for "hybrid" aortic debranching during endovascular repair of thoracic and thoracoabdominal aortic aneurysms. J Thorac Cardiovasc Surg. 2008;136:21-8.

19. Patel HJ, Upchurch GR Jr, Eliason JL, Criado E, Rectenwald J, Williams DM, et al. Hybrid debranching with endovascular repair for thoracoabdominal aneurysms: a comparison with open repair. Ann Thorac Surg. 2010;89:1475-81.

20. Siegenthaler MP, Weigang E, Brehm K, Euringer W, Baumann T, Uhl M, et al Endovascular treatment for thoracoabdominal aneurysms: outcomes and results. Eur J Cardiothoracic Surg. 2008;34:810-9.

21. Healthcare Cost Utilization Project, Nationwide Inpatient Sample (NIS). Rockville (MD): Agency for Healthcare Research and Quality; 2001.

22. International Classification of Diseases, Ninth Revision, Clinical Modification, Fifth Edition. Washington (DC): US Department of Health and Human Services, Public Health Service; 1988.

23. Cowan JA Jr, Dimick JB, Henke PK, Huber TS, Stanley JC, Upchurch GR Jr Surgical treatment of intact thoracoabdominal aortic aneurysms in the United States: hospital and surgeon volume-related outcomes. J Vasc Surg. 2003;37: 1169-74.

24. Canaud L, Alric P, Gandet T, Albat B, Marty-Ane C, Berthet JP. Surgical conversion after thoracic endovascular aortic repair. J Thorac Cardiovasc Surg. 2011; 142:1027-31.

25. McPhee J, Eslami MH, Arous EJ, Messina LM, Schanzer A. Endovascular treatment of ruptured abdominal aortic aneurysms in the United States (2001-2006) a significant survival benefit over open repair is independently associated with increased institutional volume. J Vasc Surg. 2009;49:817-26. 
APPENDIX TABLE 1. Geographic regions

Geographic

$$
\text { region }
$$

States

Northeast ME, NH, VT, MA, RI, CT, NY, NJ, PA

Midwest $\quad$ OH, IN, IL, MI, WI, MN, IA, MO, ND, SD, NE, KS

South DE, MD, DC, VA, WV, NC, SC, GA, FL, KY, TN, AL, MS, AR, LA, OK, TX

West MT, ID, WY, CO, NM, AZ, UT, NV, WA, OR, CA, AK, HI

US geographic regions are those described on the Nationwide Inpatient Sample database Web site (http://www.hcup-us.ahrq.gov/db/vars/h_region/nisnote.jsp).

\begin{tabular}{lllr}
\hline & \multicolumn{3}{c}{ Hospital bed size } \\
\cline { 2 - 4 } Location and teaching status & Small & Medium & Large \\
\hline Northeast region & & & \\
$\quad$ Rural & $1-49$ & $50-99$ & $100+$ \\
$\quad$ Urban, nonteaching & $1-124$ & $125-199$ & $200+$ \\
$\quad$ Urban, teaching & $1-249$ & $250-424$ & $425+$ \\
Midwest region & & & \\
$\quad$ Rural & $1-29$ & $30-49$ & $50+$ \\
$\quad$ Urban, nonteaching & $1-74$ & $75-174$ & $175+$ \\
$\quad$ Urban, teaching & $1-249$ & $250-374$ & $375+$ \\
Southern region & & & \\
$\quad$ Rural & $1-39$ & $40-74$ & $75+$ \\
$\quad$ Urban, nonteaching & $1-99$ & $100-199$ & $200+$ \\
$\quad$ Urban, teaching & $1-249$ & $250-449$ & $450+$ \\
Western region & & & \\
$\quad$ Rural & $1-24$ & $25-44$ & $45+$ \\
$\quad$ Urban, nonteaching & $1-99$ & $100-174$ & $175+$ \\
$\quad$ Urban, teaching & $1-199$ & $200-324$ & $325+$ \\
\hline Hospital bed size categories are those described on the Nationwide Inpatient Sample \\
database Web site (http://www.hcup-us.ahrq.gov/db/vars/hosp_bedsize/nisnote.jsp).
\end{tabular}

